\title{
Aurora Wolfgang; Gender and Voice in the French Novel, 1730-1782
}

Richard A. Francis

\section{(2) OpenEdition}

1 Journals

\section{Édition électronique}

URL : https://journals.openedition.org/studifrancesi/26281

DOI : 10.4000/studifrancesi.26281

ISSN : 2421-5856

Éditeur

Rosenberg \& Sellier

\section{Édition imprimée}

Date de publication : 1 avril 2007

Pagination : 176

ISSN : 0039-2944

\section{Référence électronique}

Richard A. Francis, «Aurora Wolfgang; Gender and Voice in the French Novel, 1730-1782 », Studi Francesi

[En ligne], 151 (LI | I) | 2007, mis en ligne le 30 novembre 2015, consulté le 23 novembre 2021. URL : http://journals.openedition.org/studifrancesi/26281; DOI : https://doi.org/10.4000/studifrancesi. 26281

Ce document a été généré automatiquement le 23 novembre 2021.

\section{(c) (†) $\ominus$}

Studi Francesi è distribuita con Licenza Creative Commons Attribuzione - Non commerciale - Non opere derivate 4.0 Internazionale. 


\title{
Aurora Wolfgang; Gender and Voice in the French Novel, 1730-1782
}

\author{
Richard A. Francis
}

\section{RÉFÉRENCE}

AURORA WOLFGANG; Gender and Voice in the French Novel, 1730-1782, Aldershot, Ashgate, 2004 ; pp. X +210 .

1 Le but de cette étude, que nous présentons avec un retard dont nous nous excusons, est de montrer comment, à l'époque en question, les femmes utilisent la narration à la première personne pour cultiver un style naturel qui fait contraste avec les genres formels préférés par les hommes. Les romancières réussissent à imposer un mode d'écriture, basé sur le discours de la sociabilité et le pouvoir révélateur de la voix féminine spontanée, qui trouvera des adhérents même parmi les romanciers. Dans un premier chapitre, l'auteur trace les débuts de cette évolution au dix-septième siècle, où le style masculin, dominé par l'érudition, l'église, l'art oratoire et le latin, fléchit devant le style conversationnel des salons, l'analyse psychologique, les idéaux de la politesse et la promotion de valeurs littéraires fondées sur l'instinct plutôt que sur les règles. Ce goût essentiellement aristocratique est contesté vers la fin du dix-huitième siècle par des attitudes bourgeoises qui font de la littérature une activité commerciale. Cela ne favorise pas les femmes, et le réalisme du dix-neuvième siècle marque un retour à un idéal plutôt masculin basé sur la connaissance. Mais pendant les dernières décennies de l'Ancien Régime, cette mode créée par les femmes est la force la plus dynamique dans le roman, et elle s'avère capable d'engendrer une vraie profondeur. Quatre auteurs sont étudiés à fond pour illustrer cette thèse. Marivaux, utilisant sciemment le style féminin pour donner une voix à ses attitudes modernes, crée avec sa Marianne un personnage qui réunit le naturel et la coquetterie au moyen du double registre. Malgré la spontanéité apparente de son style apparemment intuitif qui accommode des changements rapides de sujet à la mode de la conversation, on y reconnaît cependant un artiste masculin raffiné pour qui le style féminin est un exercice rationnel. Là où 
Marianne cache l'effort artistique, la Zilia de Mme de Graffigny révèle franchement le travail qu'exige la composition; création d'une femme de lettres qui veut faire carrière dans un monde qui n'est pas très accueillant, les Lettres d'une Péruvienne, histoire d'une femme voulant connaître la société française par la conversation mais obligée par l'indignité de ses interlocuteurs d'avoir recours aux livres, combine le roman sentimental avec le roman intellectuel. Les deux éléments restent cependant séparés, preuve de la difficulté que rencontrent les femmes qui veulent adopter la langue des connaissances intellectuelles. Fanni Butlerd, femme séduite et abandonnée, mais forte, qui sait trouver un plaisir quasi érotique dans le processus d'écrire, conteste les stéréotypes du style féminin tout autant qu'elle s'y conforme. S'efforçant de garder un semblant de spontanéité, l'art très calculé de Mme Riccoboni ne la protège pas, même aujourd'hui, de la supposition fort douteuse que son œuvre apparemment naturelle doit forcément avoir un caractère autobiographique. Laclos enfin, dans Les Liaisons dangereuses, veut remplacer le sentiment féminin par un réalisme masculin. Une analyse du style des trois principaux personnages féminins de ce roman révèle trois genres contrastés de sexualité féminine, tous prenant leur origine dans le corps, même la cérébralité voulue de Mme de Merteuil. La thèse, richement illustrée, est présentée de façon persuasive, offrant un outil efficace pour l'analyse des mouvements littéraires de l'époque. Certains lecteurs pourraient la trouver un peu schématique, mais elle est agréable à lire et ses arguments, toujours stimulants, méritent une réflexion sérieuse. 